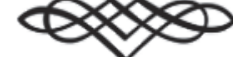

We have Defeated Oblivion: On Digital Immortality

\title{
Hemos derrotado al olvido: sobre la inmortalidad digital
}

\author{
Lorena Rojas Parma
}

Universidad Católica Andrés Bello lorojas@ucab.edu.ve

DOI: https://doi.org/10.15366/bp2021.27.017

Bajo Palabra. II Época. No 27. Pgs: 323-348

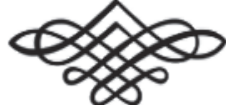


Recibido: 08/03/2021

Aprobado: 07/05/2021

\section{Resumen}

La preocupación humana por la inmortalidad tiene una larga historia. En nuestros tiempos, con las promesas de la biotecnología y el transhumanismo, se nos anuncia una posibilidad de cumplir con ese sueño del corazón humano. Con todo, hoy, sin los complejos procesos que se implican en esas promesas, contamos con una tecnología que nos permite dar cuenta de nuestra vida en un sentido inmortal. Por toda la "eternidad digital" habrá pruebas de que vivimos: fotos, videos, búsquedas, conversaciones y un largo etcétera, nos resguardarán por siempre del abismo del olvido. Los registros dejados en nuestras cuentas virtuales van a permanecer en la red, y una inmortalidad digital protegerá nuestro paso por la tierra. El artículo se propone explorar esta experiencia y sus posibles consecuencias.

Palabras clave: inmortalidad, budismo, virtualidad, olvido, recuerdo.

\section{Abstract}

The human concern for immortality has a long history. In our times, however, with the promises of biotechnology and transhumanism, a possibility is announced to us of fulfilling that dream of the human heart. Yet today, without the processes involved in those promises, we have a technology that allows us to think our lives in an immortal sense. For all "digital eternity" there will be proof that we lived: photos, videos, searches, conversations and a long etcetera, they will protect us from the abyss of oblivion. The records will remain on the network, and a "digital immortality" will protect our passage through the earth. The article aims to explore this experience and its possible consequences.

Keywords: Key Word: Immortality, Buddhism, Virtuality, Oblivion, Memory. 
Hice que los mortales dejaran de andar pensando en la muerte antes de tiempo

Prometeo, en Prometeo encadenado

Algo que va lejos, que circula solo, sin cuerpo, que tiene como cobijo el escondite del corazón: eso es el pensamiento; los que lo dominan quedan liberados de las ataduras de la muerte

Buda, Dhammapada

\title{
$\alpha$. El rugido de león
}

\author{
Tú piensas \\ que el Surgimiento Condicionado es la Vaciedad. \\ No existe un ser no-dependiente: \\ este es tu sin igual Rugido de León. ${ }^{1}$
}

Así escribe NāGĀRjuna a su maestro Buda en uno de los versos que concentra el corazón de los postulados del budismo mahāyāna: la vaciedad, la causa necesaria de las cosas y su consecuente dependencia. De lo que se concluye que todo es ilusorio, pasajero o efímero, porque, en realidad, todo es sünyatā, vaciedad. Según el argumento, si todo está sujeto a aparecer y desaparecer, a existir de manera temporal -nada en el mundo es causa sui-, todo tiene una existencia dependiente. El surgimiento condicionado, es decir, el venir a la existencia, siempre depende de una causa, está "condicionado" por esta y, como es bien sabido, todo lo que tiene causa también tiene fin. Venir a la existencia y eventualmente perecer significa, es evidente, cambio, acontecer, fluir, dejar de ser lo que se ha sido. ${ }^{2}$ Para el pensamiento budista y de India, en general, esos son síntomas de irrealidad, de vacío, pues las cosas nunca son en su inestabilidad, nunca se serenan en su devenir y, por lo tanto, no son reales. En efecto, "la mentalidad hindú -escribe Zimmer-asocia

\footnotetext{
${ }^{1}$ Nāgārjuna, Lokātitastava, Estrofa 22, en Tola, F., y Dragonetti, C., (compiladores y traductores): Filosofía budista, Buenos Aires, Las cuarenta, 2012, p. 169. Las referencias a los himnos de Nāgārjuna pertenecen a esta edición.

${ }^{2}$ Cfr. Arnau, J., La palabra frente al vacio. Filosofía de Nägärjuna, México, Fondo de Cultura Económica, 2005, pp. 109 y ss.
} 
ideas tales como 'transitorio', 'cambiante', 'fugaz', 'cíclico' con 'irrealidad'; y viceversa, 'imperecedero', 'inmutable', 'firme' y 'eterno' con lo 'real'”. ${ }^{3}$ La pregunta necesaria es, entonces, qué es lo real, pues nada en el mundo es imperecedero, firme o eterno. Incluidas nuestras experiencias. La conocida respuesta budista $-\mathrm{y}$ que enfatiza Nāgārjuna- es que todo es ilusorio, pues esa fragilidad e impermanencia de las cosas solo da cuenta de su vaciedad. Por lo tanto, la vida y todo nuestro mundo son "similares a la espuma, a una burbuja, a una ilusión mágica, a las nubes, a un espejismo, a la kadal $\overrightarrow{\text { ". }}{ }^{4}$

Ese es el rugido de león, el temible grito de la vaciedad de la existencia, de la naturaleza vacía de lo que somos y lo que nos rodea, de su insustancialidad y su falta de consistencia. De la vaciedad de todas nuestras experiencias. Amargas o felices, íntimas o compartidas, conmovedoras o superficiales todas son, en última instancia, igualmente pasajeras, inestables, susceptibles de descomposición, ${ }^{5}$ vaciedad. La evidencia profunda de un amor o de una ley física, así como nuestra conciencia, sensibilidad, percepciones o emociones, no escapan de la verdad del vacío. ${ }^{6}$ De la naturaleza de lo que ahora es y luego no existe, de lo que nunca se mantiene igual a sí mismo. Si todo, entonces, se revela vaciedad, tendremos que sostener, también, que todas las experiencias son igual de reales, auténticas o valiosas. Pues no podríamos asumir experiencias "más verdaderas" que otras o que algunas sean reales y otras no, pues desde la realidad de lo insustancial, todas "son" experiencias. En efecto, desde la vaciedad todo se revela horizontal, se desvanecen las jerarquías en lo que existe o en lo que se asume "verdadero". 7 La única crítica consiste en mostrar, a partir del análisis del mundo, que todo, finalmente, es condicionado e ilusorio. ${ }^{8}$

\footnotetext{
3 Zimmer, H., Mitos y simbolos de la India, Madrid, Siruela, 2008, p. 33.

${ }^{4}$ Achintyastava, op. cit., verso 18, p. 195.

5 Alusión a la tesis del canon budista según la cual nada cuenta con ser propio o sustancialidad. Así, por ejemplo, una cuerda no es una cuerda -aunque inicialmente la percibamos-, pues solo nombra un conglomerado de elementos en los que se puede descomponer y que, a su vez, también se descomponen. Por lo tanto, ni la cuerda ni los elementos que la constituyen tienen existencia propia. En general, el mundo y todo lo que percibimos no es más que un agregado que, al ser analizado, se desvanece y se devela vacío. Cfr. Bareau, A., Buda, vida y pensamiento, Madrid, Edaf, 1981, pp. 174 y ss. Cfr. Comentario del tratado denominado 'El pelo en la mano', de Äryaveda, en Tola, F., y Dragonetti, C., op. cit., pp. 75 y ss. Sobre este método analítico-abolitivo, cfr. pp. 36 y ss.

${ }^{6}$ Cfr. estrofas 2-3, Lokātitastava, op. cit., p. 160. Cfr. Garfield, J.L., The Fundamental Wisdom of The Middle Way, Oxford, Oxford University Press, 1995, p. 88. "La vacuidad y el surgir-inter-dependiente no son realidades absolutas, son designaciones lingüísticas convencionales o conceptos funcionales, tan vacíos de existencia substancial como todas las demás cosas", Vélez de Cea, A., "Nāgārjuna y la filosofía del Buddha", en Contrastes, Revista internacional de filosofía, Universidad de Málaga, Vol. 3, 1998, p. 267.

7 Cfr. estrofa 4, Niraupamyastava, op. cit., p. 174. Sobre los testimonios de Buda con relación al condicionamiento, a la "producción condicionada", cfr. Bareau, A., op. cit., pp. 174-179; Gómez Fernández, A., "Nagarjuna y la dialéctica del origen condicionado", en Pensamiento, Universidad de Comillas, Vol. 64, 2008, pp. 872 y ss.

8 "La Vaciedad no es diferente de las cosas, y ninguna cosa existe sin ella, por eso Tú has enseñado que las cosas nacidas en dependencia son vacías", estrofa 43, Achintyastava, op. cit., p. 205.
} 
Estos argumentos diluyentes de la existencia, que rugen vacío, nos llegan desde el fluir del Ganges, "que corre sin cesar, bello y libre". ${ }^{9}$ Con todo, no nos resultan totalmente extraños: nos traen al espíritu ecos de Parménides, de aquel color vivo del que nos habla en su poema, que en su existir inconcebible de "no ser" siempre cambiante, se va haciendo cada vez más tenue. El cambio, el nacimiento y la muerte, dice el filósofo, no son más que simples nombres. ${ }^{10}$ Por lo tanto, el palidecer del color, el desdibujarse de sí, nunca puede ser la verdad, pues ella solo lleva consigo la inmovilidad eterna de un "corazón que no tiembla". ${ }^{11} \mathrm{La}$ intuición profunda del eleático que se opone a la existencia del devenir de la experiencia es -nada menos que- la existencia única de lo que es; la del Buda, por su parte, el vacío, sünyatā. ${ }^{12}$

Ahora, sin embargo, en lugar de analizar el mundo para corroborar su inexistencia me interesa explorar, desde el argumento de Nāgārjuna, las experiencias virtuales, pues, como cualquiera de nuestras experiencias, se nos revelan igualmente "auténticas". No pueden ser asumidas como sustituciones de las experiencias "reales", como medicinas temporales para la ausencia, o como algún tipo de prótesis de la presencia, porque finalmente comparten la misma "naturaleza" de la "realidad": dependiente, condicionada, sūnyatā. Lo que nos impide, en rigor, hacer distinciones definitivas entre lo que llamamos real y virtual. La tecnología digital nos ha permitido experimentar maneras inéditas de estar presente, de estar ahi, de acompañar al otro, aunque estemos geográficamente distantes, y ha traído consigo la extraordinaria posibilidad de que nuestras interacciones y registros digitales permanezcan en la red de manera intemporal. Podemos registrar nuestra vida, guardar episodios de nuestro día a día, en un "espacio" que los resguarda en una suerte de eternidad que permite lo digital. Por lo tanto, lo dependiente, lo condicionado, lo que inevitablemente

\footnotetext{
9 Palabras de Visvamtra a Rama sobre el Ganges, en Wilkins, H., Mitología hindú, Barcelona, Edicomunicación, 1998, p. 338.

${ }^{10}$ Cfr. versos 35-40, en De Tales a Demócrito: fragmentos presocráticos, Madrid, Alianza, 1998, p, 164. Traducción de Alberto Bernabé. Con relación al verso 40, dia ta chroa phanon ameibein, "variar de color resplandeciente", cfr. el hermoso comentario de Gadamer en El inicio de la filosofía occidental, Barcelona, Paidós, 1995, pp. 130131.

11 Verso 25, op. cit., p. 161. Atremes etor.

12 En el caso de Nāgārjuna y su "vía del medio", de la escuela Mādhyamaka, hablamos más que de no-ser, como los eleáticos, de lo que solo aparece, es dependiente y no tiene ser propio. De lo que es solo vaciedad y, tal vez, un falso ser. Cfr. Estrofa 21, Niraupamyastava, op. cit., p. 182. Cfr. Kalupahana, D., The Philosophy of The Middle Way, Albany, State University of New York Press, 1986, pp. 1-99; Parain, B., (compilador): Historia de la filosofía, México, Siglo XXI, 1990, pp. 111 y ss.; Robinson, R., Johnson, W., The Buddhist Religion, Belmont CA, Wadsworth Publishing Co, 1997, pp. 82-90; Harvey, P., El budismo, Cambridge University Press, traducción española, 1998, pp. 122-130; Walser, J., Nāgārjuna in context: Mahāyāna Buddhism and The Early Indian Culture, New York, Columbia University Press, 2005, pp. 224 y ss.
} 
está destinado a desaparecer, ahora puede permanecer. Y si la vida biológica y la vida digital son un agregado de elementos susceptible de descomposición que conduce al vacío, significa, entonces, que no podemos demarcar fronteras con lo virtual, y que nosotros, además, podremos permanecer. Estamos hablando, en consecuencia, de una nueva versión de la inmortalidad a través de la tecnología digital. De sus redes, es sabido, nada desaparece; y permaneceremos allí sin tiempos definidos. ${ }^{13}$

Pero el rugido de león no deja de advertirnos de la naturaleza fugaz, condicionada y vacía de todo lo que "existe". Pues inescapablemente todo es sūnyatā. Incluso esa eternidad digital que también tiene causa y podría llegar a su fin en algún colapso que sufra el mundo. Pero mientras exista, junto al rugido que nos llega de India, podemos ir despejando el camino para mostrar, en lo posible, esas relaciones entre nuestra vida biológica y nuestro registro digital. Entre esta vida que respira y la vida digital. Para poder, finalmente, preguntarnos: ¿cuál es la diferencia entre la vida que hoy publicamos en las redes y la que eternamente dará cuenta virtual de nosotros? ¿Qué significa para lo humano, como lo hemos conocido, esta nueva eternidad digital?

\footnotetext{
13 Son conocidos los vínculos entre la filosofía budista, la ciencia y la tecnología. De manera puntual me gustaría recordar a Masahiro Mori y The Buddha in the Robot (Tokyo, Kosei Publishing, 1985), donde se nos presenta una hermosa disertación sobre textos del Sutra del Loto a partir de los hallazgos del autor durante la construcción de un robot. Asimismo, recodar una noticia de 2016 donde se nos informa que en un templo budista de Beijing, apareció Xian'er, un monje-robot elaborado por un grupo de especialistas en inteligencia artificial de universidades chinas. Y referir, finalmente, desde las neurotecnologías, a Hughes, J., Using Neurotechnologies to Develop Virtues - A Buddhist Approach to Cognitive Enhancement, https://ieet.org/index.php/IEET2/more/ hughes20121016, donde se plantea la posibilidad de alcanzar lo que se propone el budismo a través de muchos años de práctica y meditación, mediante la tecnología futura del transhumanismo. Cfr. Mazocco, R., Transhumanism, Engineering the Human Condition, Springer Praxis Books, 2019. Por su parte, Yuval Noah Harari, en Homo Deus, mientras describe el uso de electrodos en el cerebro humano a través de un casco, alude a un episodio que se implica con lo que ahora nos ocupa. Una periodista sin ningún entrenamiento bélico entra a una sala de simulación de un campo de batalla, con el casco de electrodos adherido a su cuero cabelludo. "Informa que no notaba nada extraño, excepto un ligero hormigueo y un raro sabor metálico en la boca. Pero empezó a cazar a los terroristas de uno en uno, tan fría y metódicamente como si fuera Rambo o Clint Eastwood. 'Cuando veinte de ellos corren hacia mí blandiendo sus armas, apunto serena con el rifle, me tomo un momento para respirar profundamente y le doy al más cercano, antes de elegir con calma mi siguiente objetivo' [...] En los días siguientes se dio cuenta de que había pasado por una 'experiencia casi espiritual [...]; lo que definía la experiencia no era sentirse más listo o aprender más deprisa: lo que hizo que la tierra desapareciera bajo mis pies fue que, por primera vez en mi vida, en mi cabeza todo se habia callado al fin. [...] $\mathrm{La}$ ausencia de inseguridad en mi cerebro fue una revelación. De repente se hizo aquel silencio increíble en mi cabeza [...]. Espero que puedan comprenderme, pero lo que más ansiosamente deseé durante las semanas que siguieron a mi experiencia era volver y conectarme de nuevo a aquellos electrodos", Harari, Y. N., Homo Deus, Penguin Random House, 2016, pp. 303-304. Cursivas añadidas. Lo que logra la periodista a través del casco, la experiencia espiritual que describe, el silencio en su cabeza, la ausencia de inseguridad, la concentración y el tino es, precisamente, a lo que aspira la paciente práctica budista y su meditación. Tal vez no para ser Rambo, pero sí para hallar ese estado de autocontrol que permite la atención y la mente serena. Por si fuera poco, la periodista comenzó a hacerse preguntas sobre quién era, sobre su identidad, para concluir nada muy distinto de lo que concluye el budismo.
} 


\section{$\beta$. No nos olviden}

Es UN LUGAR COMÚN decir que la vida se ha visto conmovida en sentidos muy complejos por la tecnología digital. Esa conmoción, sin embargo, no implica una perturbación totalmente ajena a su propio sentido: quiero decir, con las hazañas digitales estamos, también, en presencia de sueños muy profundos del corazón humano, de anhelos que lo acompañan desde muy antiguo. Pensemos en lo que significa espiritualmente poder estar junto al amado, a pesar de la distancia; en nuestros mensajes urgentes recibidos de inmediato en su destino; en nuestras opiniones sobre la vida publicadas en segundos; en la compañía que nos puede aliviar en medio de alguna soledad difícil de sobrellevar. Son solo unos ejemplos, sin duda, pero reveladores de lo que hemos conquistado. $Y$ aunque ocurran en un tiempo distinto del humano, no son extraños a nuestros viejos deseos, al alma dionisíaca y creadora que siempre se ha hecho sus teatros para poder vivir. Aprendimos muchas artes, como lo vaticinó Prometeo, y la techne se mostró, así, una condición de lo humano. "Si 'hay' hombre -escribe Sloterdijk- es porque una tecnología lo ha hecho evolucionar a partir de lo prehumano. Ella es la verdadera productora de seres humanos, o el plano sobre el cual puede haberlos". ${ }^{14}$

Hoy, desde esta humanidad prometeica, podemos llevar registros digitales de nuestra vida y dejarlos como testimonio inequívoco de nuestra existencia. Sin ser faraones o conquistadores, príncipes o grandes artistas, hoy todos tenemos acceso a uno de los más antiguos anhelos del espíritu humano, la inmortalidad. No es necesario justificar ese anhelo que atraviesa culturas diversas de formas igualmente diversas, y que tampoco es extraño a la filosofía. Basta con evocar la decisión de Aquiles por la gloria, la eternidad del alma pitagórica o platónica, el Mausoleo de Halicarnaso, la resurrección cristiana, las plegarias de las pirámides de Egipto, el Taj Mahal y una incontable cantidad de ejemplos, muy distintos entre sí, para reconocer ese sueńo de ser recordados o de permanecer, de alguna manera, tras la muerte. ${ }^{15}$ Hoy, decíamos, con una vida discreta y sin grandes hazañas, nuestro

${ }_{14}$ Sloterdijk. P., "El hombre operable", conferencia dictada en el Center of European Studies de la Universidad de Harvard, 19-5-2000, p.14. http://www.observacionesfilosoficas.net/download/hombreoperable.pdf.

15 Antonio Diéguez comienza su libro Transhumanismo, haciendo un número importante de preguntas que conmociona el corazón de la vida, la que ha sido y la que está por venir. La primera que se plantea, y tal vez la más provocadora es, justamente, "¿Qué le parecería a usted tener una vida de duración indefinida y permanecer siempre joven y sano, hasta el punto de poder considerarse inmortal?" Se alude a la fuerza que guarda siempre la posibilidad de "no morir", que ahora quiero resaltar, y que tiene que ver con viejos deseos de inmortalidad. "No morir" puede referirse a no morir biológicamente -a lo que aspira el transhumanismo-, a no morir metafísicamente -a lo que aspira el alma inmortal-, o a salvarse de la sepultura del olvido absoluto. A este no morir de olvido se refiere la inmortalidad digital. Un anhelo, como es sabido, de honda raigambre griega. Con todo, la pregunta de Diéguez me permite tomar cierta distancia, al menos ahora, de los planteamientos del transhumanismo. Pues la inmortalidad digital no implica intervenciones al cuerpo, ni máquinas humanas, ni 
tránsito por la tierra ya nunca se hundirá en la fosa común del anonimato. Por toda la eternidad digital habrá pruebas de que vivimos: fotos, videos, búsquedas, conversaciones y un largo etcétera, nos resguardarán por siempre del abismo del olvido. Los registros dejados en nuestras páginas o cuentas virtuales van a permanecer en la red, y van a dar cuenta de nosotros de manera intemporal. Pues una inmortalidad digital protegerá nuestro paso por la tierra. En consecuencia, sin recurrir a metafísicas, religiones, transhumanismos, biotecnologías, y sin alterar, en cierta forma, los tiempos naturales de la vida biológica, hemos hallado una manera de permanecer en la eternidad digital. ${ }^{16}$

Nos estamos refiriendo, entonces, a una inmortalidad que se enfrenta al abandono del olvido, al Hades de la eterna penumbra, y que ahora cuenta con indiscutibles testigos de nuestra existencia. No se trata de una inmortalidad metafísica, ciertamente, y aunque parezca un poco más "familiar" al espíritu de la épica griega que al platonismo o al cristianismo, por referirse -en principio-solo a lo ocurrido, cuenta con algo totalmente inédito: testimonios literales. Episodios audiovisuales conservados como ocurrieron. Inédito e insólito para un rapsoda. $\mathrm{O}$ para el poeta asistido por la Musa. ${ }^{17} \mathrm{La}$ inmortalidad digital tampoco tiene que ver, por supuesto, con la inmortalidad como procreación, según el conocido argumento de Diotima o Aristóteles. ${ }^{18}$ Esa inmortalidad, sin embargo, al igual que la digital, no reniega de los límites de la vida biológica. No hay batallas filosóficas o tecnológicas contra la muerte del cuerpo, ni es necesario que nos mezclemos "íntimamente", en el caso de la inmortalidad digital, "con la metálica y erotizada pseudocarne de

una vida prolongada con experiencias y posibilidades extraordinarias mientras aplaza la muerte biológica. No se trata de una "integración simbiótica entre el ser humano y las máquinas superinteligentes", Diéguez, A., Transhumanismo, Barcelona, Herder, 2017, pp. 7-8. Se trata, en realidad, de algo menos aparatoso y accesible ahora mismo a todos de todas las formas posibles. Incluida la económica. Asimismo, no es viable desestimar el viejo anhelo de inmortalidad que atraviesa la cultura. Posturas que asumen que se trata de una idea "superada" se sorprenden, sin embargo, por la gruesa implicación que tiene especialmente en el transhumanismo. Si aún hay que rebatir con vehemencia la fantasía de la inmortalidad personal, es evidente que no ha sido abandonada. Que aún nos conmueve. Cfr. Rodríguez González, M., "Tecnotrascendencia como ilusión narcisista”, Daimon. Revista Internacional de Filosofía, no 76, 2019. Estas experiencias transcurren, finalmente, "conforme a una serie de antiguas aspiraciones de los seres humanos, que han estado presentes desde tiempos inmemoriales. Sería cosa de pensar, nada más y por ejemplo, en la búsqueda de la inmortalidad presente en el poema sumerio de Gilgamesh (ca. 1700 a.n.e.), o en el ejemplo paradigmático del deseo de volar que mueve a Ícaro y Dédalo", Villarroel, R., "Consideraciones bioéticas y biopolíticas acerca del transhumanismo. El debate en torno a una posible experiencia posthumana", en Revista de Filosofía, Universidad de Chile, Vol, 71, 2015, pp. 179-180. Cfr. la introducción sobre Gilgamesh versus Dragon-Tyrant, en Manzocco, R, op. cit., pp. vi-xvi. Son sueños y apariciones que vienen con nosotros desde siempre, y que han labrado su camino hasta nuestros días.

16 Sobre las posibilidades actuales contra el envejecimiento del cuerpo, y la pretensión del transhumanismo de prolongar su vida biológica útil, cfr. Manzocco, R., op. cit, pp. 97 y ss.: "The Phoenix 2.0".

17 Cfr. Ion, 533d-535a. La referencia a los diálogos platónicos es de Platone, Tutte le opere, Roma, Grandi Tascabili Economici, 1999. Edición bilingüe. En español, Platón, Ion, Madrid, Gredos, 1981.

${ }^{18}$ Cfr. Banquete, 206c-209c; Acerca del alma, 415a25-415b. Todas las citas a Banquete, se refieren a Platón. Platón, Banquete, Madrid, Gredos, 1997; Aristóteles, Acerca del alma, Madrid, Gredos, 1994. 
robots". ${ }^{19}$ Pero las diferencias son, sin duda, evidentes, pues los testigos fieles que guarda la eternidad digital de nuestra existencia no son los hijos que quedan en nuestro lugar, como reza el argumento filosófico griego, ni el eros de la vida que busca su reproducción. Se trata de testimonios de nuestra vida, que publicamos -o que publican- en la red y que se conservan en la posteridad digital. Diotima destaca, finalmente, la superioridad de la inmortalidad de los "hijos" intelectuales, es decir, de los "bellos discursos" que se conciben y se traen a la vida en el alma, junto al amado y gracias a la belleza ${ }^{20}$. Pero es una inmortalidad intelectual para espíritus como Homero, Hesíodo o Solón que, si bien hoy podríamos vincular con la eternidad digital que preserva sus textos, no representan al común de los hombres.

La inmortalidad digital no es la isla de los bienaventurados para los espíritus bellos que engrandecieron la existencia con sus hallazgos, no es su lugar de privilegio. Esa inmortalidad es para todos. Y no por nuestras grandes ideas o nuestra suprema originalidad artística o filosófica, sino porque la vida cotidiana que dejamos registrada permanece de forma inevitable e intemporal en la nube digital. Es como si la inmortalidad de Platón no se hubiera cifrado únicamente en sus diálogos, sino también en los registros de su vida cotidiana. Esto puede ser un poco aterrador. Pero supone, al mismo tiempo, un cambio interesante en la manera de concebir la inmortalidad, en la sensibilidad por los episodios del día a día de la vida, que hoy con mucha energía se registran $-y$ de inmediato se publican-. Registramos, por ejemplo, lo que comemos, dónde, con quién, acompañado del día y la hora exactos. Y no lo hacemos para nosotros, se lo publicamos al kosmos y va a permanecer allí sin término conocido. Nos hallamos, entonces, ante una inmortalidad de la vida cotidiana del hombre común, del hombre que desde su discreto lugar en el mundo registra su vida y deja su testimonio. Eso dependerá, por supuesto, de lo que cada uno decida publicar en sus cuentas o páginas digitales. En todo caso, estamos hablando de la eternidad digital de nuestras opiniones, ocurrencias, fiestas, discusiones, ceremonias, postres, viajes... Porque no hay vida tan simple que no tenga a su alcance esta inmortalidad. ${ }^{21}$

Por lo tanto, es la vida común lo que ha ganado un espacio inusitado en estos tiempos virtuales. Todos podemos publicar nuestra opinión política, nuestras sen-

19 Rodríguez, M., op. cit., p. 74.

${ }^{20}$ Cfr. Banquete, 209a-e.

${ }^{21}$ Esto me recuerda unas líneas que Rorty escribe sobre Freud: "Pues la explicación que Freud da de la fantasía inconsciente nos muestra de qué modo es posible ver la vida de todo ser humano como un poema; o, más exactamente, la vida de todo ser humano no tan oprimida por el dolor que sea incapaz de adquirir un lenguaje ni tan hundido en el trabajo que no disponga de tiempo para generar una descripción de sí mismo. Ve toda vida como un intento de revestirse de sus propias metáforas", Rorty, R., Contingencia, ironía y solidaridad, Barcelona, Paidós, 1991 p. 55. Si bien ahora no hablamos de psicoanálisis, la posibilidad que hoy tiene el hombre común es justamente esa: hacer de su vida su propio poema, describirse, contarse, además, para la posteridad. Intenta 
tencias, al modo de un magistrado del pasado. Todos podemos informar de nuestros viajes, con fotos, videos o Google Map -que da cuenta precisa de nuestro itinerario-, como si fuésemos una codiciada estrella de rock. Todos podemos hacer videos de nuestros hogares y publicarlos, al mejor estilo de la realeza que descubre su palacio al mundo. Conscientes que esos testimonios quedarán atrapados en la nube digital que ahora cubre nuestros cielos. ¿Qué significa esto? Al menos podemos decir que nuestra vida común ha conseguido un camino para abandonar el anonimato, y para mostrar sin mediaciones lo que presume como su belleza. El alma dionisíaca se ha construido siempre un escenario desde donde mostrarse y ser reconocida -exigencia primera del dios-: "Dioniso conoce la humillación de un dios que se ve tratado como un simple mortal", nos recuerda Detienne. ${ }^{22}$ El alma dionisíaca que nos alienta, entonces, parece que ha reclamado una cierta jerarquía "divina" para la vida que se desvanecía silenciosa y anónima. No reconocida. Con la tecnología digital nos hemos hecho, junto al dios del teatro, una palestra universal, cósmica, desde donde exhibirnos al orbe, pues nuestra vida ya no quiere ser tratada con la simpleza de lo mortal.

No podemos subestimar esta conquista de la vida cotidiana. Solo pensemos en los esfuerzos intelectuales modernos y contemporáneos por rescatar la vida del hombre común que transitaba por las calles de Atenas, Alejandría o el París moderno; la vida femenina de los gineceos atenienses de los que sabemos tan poco; o la vida de los esclavos que pasaron sus días bajo el mando de una voz "libre". Son ejemplos de vidas desconocidas que se hundieron para siempre en el Hades del olvido. Hoy es de un infinito valor, por supuesto, algún hallazgo de la vida cotidiana de cualquier alma anónima de la antigüedad. La vida digital es, precisamente, el antídoto contra esa muerte, pues la vida del hombre común es la que hoy también queda a resguardo del anonimato de la existencia.

Así, esta inmortalidad digital tiene que ver con el deseo de no ser olvidados, de no morir en las corrientes del río Lethes, o de no evaporarnos como las almas antiguas que, tras esa dispersión, poco o nada dejaban de su paso por el mundo. La eternidad digital ampara lo inolvidable de lo vivido, es garante de lo que hicimos, sin emprender una batalla extravagante contra la muerte. En cierta forma, este auto reportarse la vida, que quiere publicar y salvaguardar los detalles cotidianos, expresa la consciencia de la desaparición biológica, de la muerte que ha de sobrevenir y, por ello, quiere dejar su testimonio. Nos viene desde el alma profunda de la cultura este temor al olvido. Como nos lo recuerdan unas palabras de Safo, que ahora expresan un mal deseo que augura el olvido:

revestirse de sus propias metáforas, y puede sentir que su existencia, a pesar de su sencillez y la inevitable fugacidad, dejó un testigo que narrará su poema todas las veces que le sea posible.

22 Detienne, M., Dioniso a cielo abierto, Barcelona, Gedisa, 1997, p. 36. 
$\mathrm{Al}$ morir quedarás yerta y de ti nunca memoria habrá ni nostalgia en el futuro. Porque no participas de las rosas de Pieria. Mas, ignorada aun en el Hades, vagarás revoloteando por entre oscuros difuntos. ${ }^{23}$

La muerte del olvido, la del oscuro difunto sin recuerdo, es la muerte que tiene su redención en lo digital. Escapar de la vida que se esfuma, aunque estemos en el Hades, es lo que trae para las almas comunes esta nueva eternidad. Por ello, la vida que dejamos registrada, esa permanencia post mortem de lo sucedido, estará siempre a la espera de que alguien venga por ella. Es uno de los sentidos de este almacenarse de sí -en imágenes, historias, comentarios, opiniones-: la posibilidad de volverse a contar. La sobrevivencia de esa (re)colección de episodios se encargará de dar cuenta de nosotros. Podemos decir que moldeamos, de alguna manera, nuestra vida en la eternidad. Que nosotros mismos nos editamos, que nos hacemos de un perfil a nuestra medida para soñar nuestra posteridad.

Al mismo tiempo, el alma curiosa que vaya a nuestro encuentro en el más allá digital podrá, también, forjarse sobre nosotros su propia historia, podrá hacer sus propias relaciones y, tal vez lo más complejo, podrá forjarse su propio recuerdo. Este parece un horizonte de la vida que se amplía de formas inéditas, pues el trabajo vital de la memoria, sus procesos de reelaboración, sus rarezas, sus escondites, ahora se enfrentan a testimonios que se pueden recrear infinitas veces y que -si no son modificados- serán siempre idénticos. La diosa Mnemosyne tiene a su cargo la palabra que recuerda, ser guardián de lo ocurrido. Desde sus fondos misteriosos es creadora, y su decir lo mismo es cada vez distinto. Ahora, sin embargo, se las tiene que ver con una narración idéntica y constante de la vida del otro, que no solo puede cercarnos la imaginación, sino alterar el proceso mismo -vital y cambiante- del recuerdo. No podemos subestimar que tendremos siempre el resguardo del testimonio audiovisual. Y que Mnemosyne tendrá que replantearse su trabajo relator, que ya no será de vidas heroicas que podrá recrear, sino de vidas cotidianas que dejaron fiel evidencia de sus episodios elegidos.

Nosotros, sin embargo, en nuestra sobrevivencia digital, estaremos a la espera del que venga en nuestra búsqueda. Poco importa la cantidad de tiempo que haya transcurrido. Entraremos en el extraño no tiempo de lo digital, que incluso suspende el mundo como si realmente ocupásemos otro lugar. ${ }^{24}$ Si la tecnología digital ha

\footnotetext{
${ }^{23}$ Frag. 11 (58D), en García Gual, C., Antología de la poesía lírica griega, Madrid, Alianza, 2008. Trad. de García Gual.

${ }^{24}$ Como el que se detiene en medio de un pasillo mientras interactúa con alguien a través de su teléfono, por ejemplo, obstaculizando el paso sin notarlo. Es obvio que está en otro lugar, y tal vez tenga que suceder algo agresivo que le recuerde dónde tiene los pies. Estas extrañas ubicuidades son parte de las nuevas maneras de las que disponemos para estar presentes.
} 
logrado alterar tan dramáticamente el tiempo, el tiempo humano, lo ha hecho al modo de los más fervientes amantes. Son ellos los que han sabido siempre el secreto que trastorna los tiempos humanos. Que los transforma o los ignora. Los tiempos digitales son, un poco, los tiempos del amor. Así, nuestra vida intemporal permanecerá abierta al otro que quiera buscarnos, para poder narrar de nuevo nuestras historias. Como si fuésemos nuestro propio aedo, pero sin su prodigiosa y creativa memoria que, por supuesto, no es la precisión digital. La Musa inspira, recrea, no reproduce. "Díganme ahora, Musas, dueñas de olímpicas moradas", dice el poeta en la Iliada. ${ }^{25}$ Sin embargo, aunque las Musas no vengan en nuestro auxilio, aunque ellas no nos celebren como a "la estirpe sagrada de los inmortales", ${ }^{26}$ vamos a poder narrarnos de nuevo. A otro le podremos relatar cómo nos resultó la vida. "Los efímeros" ${ }^{27}$, como nos llama el Corifeo del Prometeo encadenado, hemos copiado algo a esa estirpe sagrada. Ojalá que no hayamos blasfemado de hybris. ${ }^{28}$

\section{$\gamma$. La vida y la muerte}

LA INMORTALIDAD Digital busca mantenernos a salvo del paso invisible por el mundo. De lo que se trata, parece, es de ser inolvidables. Pero ¿qué significa, en este contexto, ser inolvidable? Las redes digitales tienen el superpoder de conservar absolutamente todo, por lo tanto, son una suerte de artillería pesada contra el olvido. Allí todo se almacena y se resguarda. Por el contrario, si pensamos en lo que significa recordar, veremos que es imperioso que haya olvido, porque solo es posible recordar lo que hemos olvidado. ${ }^{29}$ Así recuerda el esclavo de Menón el teorema de Pitágoras, y el amante del Fedro cuando se estremece ante la belleza del amado, la que contempló en el pasado durante su viaje maravilloso por la "llenura de la verdad". ${ }^{30}$ El olvido es una potestad de la memoria. Y la memoria que busca dentro de sí lo vivido, mientras lo recuerda y lo recrea, aún es patrimonio de lo humano. $\mathrm{O}$

\footnotetext{
${ }_{25}$ Homero, Iliada, Madrid, Gredos, 1991, 2, 484.

26 Hesíodo, Teogonía, Madrid, Gredos, 1990, 105.

27 Esquilo, Prometeo encadenado, Madrid, Gredos, 2006, v 250.

${ }^{28}$ Con todo, no podemos omitir lo que se nos advierte desde el transhumanismo: "And let's not forget about all of the 'brain machines,' technologies already available: the list includes Neurofeedback, that is, devices like Muse, which allow users to influence their own brain waves; Transcranial Magnetic Stimulation (TMS), which involves temporarily depolarizing neurons in the brain with electro- magnetic coils; Transcranial Direct Current Stimulation (TDCS), based on the pas-sage of low levels of current directly through the scalp; Deep Brain Stimulation (DBS), Brain Machine Interfaces (BCI) and Memory Prosthetics - basically, an artificial hippocampus -, all brain implants that have already been developed and that can be used to influence our behavior and our cognitive skills", Manzocco, R., op. cit., p. 224.

${ }^{29}$ Cfr. Chrétien, J.-L., Lo inolvidable y lo inesperado, Salamanca, Sígueme, 2002, pp. 62-63.

30 Platón, Menón, Gredos, Madrid, 1999, 82a-86b; Platón, Fedro, Madrid, Gredos, 1997, 248b. Aletheias pedion.
} 
de las Musas. Pues la imprecisión creativa del recuerdo, le es extrańa al dios digital. Él es dueño, sin embargo, de lo que inspira esta eternidad, es el celoso custodio del no olvido absoluto, el dios de lo inolvidable. Asimismo, podemos decir también, con Jean-Louis Chrétien, que lo inolvidable lleva consigo "la claridad misma del futuro". ${ }^{31}$ Lo inolvidable, sin duda, tiende al futuro, como el amor, porque no tiene fin conocido, porque ya sucedió y, al mismo tiempo, porque se abre a un horizonte desconocido. Lleva consigo un aura de eternidad.

Por ello, recurrir a la experiencia que expresa alastos, la palabra griega que traduce lo "inolvidable", puede arrojarnos algunas luces. En efecto, alastos tampoco alude a una propiedad de la memoria, en realidad, se refiere a las experiencias que, como afirma Chrétien, "no se dejan aventar, en la medida en que nuestra capacidad de olvidar resulta aquejada por ellas de incapacidad e impotencia. En este sentido, no es propiamente un recuerdo". ${ }^{32}$ Es una propiedad de lo vivido, de lo que no nos abandona y no deja de arrebatarnos. De lo que no tiene espacio ni tiempo definidos. Se lo escuchamos decir a Edipo, desde su duro peregrinar por Colono: "He sufrido lo inolvidable". ${ }^{33}$ Todos conocemos a Edipo: ¿cuál es el tiempo de ese dolor? ¿Cuál el espacio? Hay en alastos una simultaneidad, una presencia constante, que mientras evoca lo ocurrido todavía ocurre y no se vislumbra su desaparición. Fusiona los tiempos de tal modo que también vence las fuerzas del olvido. Esa simultaneidad no sabe de ciclos regulares, de tiempos definidos; y como tampoco sabe del olvido, no puede ser un recuerdo. Lo inolvidable es, así, la simultaneidad e intemporalidad de lo sucedido, lo que sobrevive en la imprecisión de espacios y tiempos que no necesita. Y es una propiedad que hoy detenta lo digital, que no olvida -de eso se trata-, que fusiona los tiempos de modos casi incomprensibles y se abre a un futuro novedoso. La eternidad digital comienza a ser nuestro "inolvidable", de una manera que supera, con creces, lo humano.

Esto nos trae a la discusión, por supuesto, la célebre advertencia platónica: los testimonios digitales van a repetirse y no podrán defenderse por sí mismos, como ocurre con las letras. Un invento de aquel ingenioso dios de Egipto, Theuth, quien con entusiasmo las presenta a su rey como presunto pharmakon para el olvido. El rey Thamus dice, sin embargo, que las letras no serán realmente un pharmakon, tan solo un hypomnestikos, un simple "recordatorio", pues la memoria ya no será dueña de su saber, ahora confiado a letras ajenas que solo podrán decir lo mismo. ${ }^{34}$ De esta misma manera, la inmortalidad digital también preservará nuestros testimonios $\mathrm{y}$,

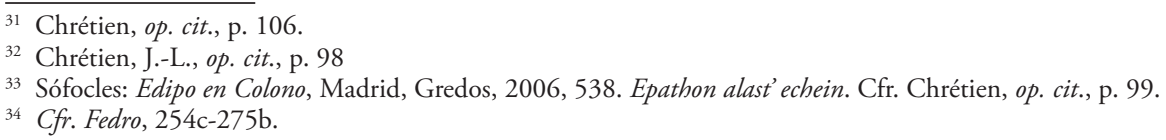


si no son modificados, van a decir siempre lo mismo. Es cierto: el trabajo de la memoria tendrá que vérselas con un saber del otro que permanece intemporal en una red digital, forjará un recuerdo a través de esos testimonios, y ya no buscará dentro de sí el saber profundo de lo que se recuerda. Acaso todo nuestro destino digital no sea más que un "recordatorio". Pero ante la desaparición absoluta de la vida, especialmente para el hombre común, un recordatorio es ya una proeza. Estamos hablando de la permanencia pública e intemporal de testimonios para el que nunca nos conoció, y que van a cumplir la promesa de salvarnos de ser un "oscuro difunto" que se pierde para siempre en el Hades. Tal vez se trate solo de eso.

Los testimonios digitales pueden permanecer idénticos en la red de la posteridad, sin duda, pero también pueden cambiar. Como lo sabemos desde Heráclito, no hay algo en el mundo que esté a salvo del devenir. Fotos o videos, por ejemplo, pueden ser tomados de nuestros espacios digitales, ser intervenidos y comenzar a interactuar en otras redes y con otras personas. Esos testimonios podrán, entonces, aparecer distintos y contar otras historias. De manera que nuestra vida post mortem tendrá su propio destino, hará sus propias relaciones, tendrá sus colores, siluetas o palabras. No tendremos control sobre nuestra posteridad, y seguiremos relacionándonos con desconocidos. Lo interesante de todo esto es la "vitalidad" que también se conserva y se implica al seguir interactuando indefinidamente de formas inesperadas. Pues si ese es el destino, no dejaremos de cambiar y narrar nuevas historias. Y como nada de esto es ajeno a la vida - por el contrario-, parece que seguiremos "viviendo" a pesar de la muerte biológica. También parece, en consecuencia, que lo biológico no es imprescindible para la vida.

Es entonces cuando escuchamos el rugido de león, que se pregunta por la realidad de la vida biológica, de todo tipo de vida, de la existencia misma de algo, y que nos permite ahora preguntamos, con él, ¿̨cuál es la diferencia entre esa vida que nos sobrevive y esta que, aquí y ahora, estamos viviendo? Además, si la inmortalidad está dispuesta a nuevos destinos, si vamos a seguir fluyendo en las redes digitales, ¿cómo nos van a recordar? ¿Seremos realmente "pasado"? ¿Nos recordarán como recordamos al que está vivo, esto es, siempre cambiando? En ese caso, ¿estaremos vivos o muertos? Nuestros testimonios digitales, además, implican inevitablemente al otro: si están ahí para mostrarse, están ahí para que se comenten. Están siempre abiertos al otro. Y, tras nuestra muerte, esas interacciones van a seguir ocurriendo. El otro va a seguir hablándonos y comentando nuestros testimonios, y especialmente si estos son modificados, nuevos comentarios seguirán surgiendo hacia nosotros y entre sí. Por lo tanto, ¿qué diferencia hace en esas interacciones digitales, que estemos vivos o muertos? Si nuestra vida cotidiana se despliega inevitablemente hoy en el espacio digital, ¿qué distingue, en rigor, que estemos vivos o muertos? Estamos, así, muy 
próximos a la pregunta filosófica por la vida y la muerte. Y en estos extrańos predios digitales, parecen lo mismo. Al hallarnos ante esta emergencia, hay que mencionar de nuevo otro león que viene desde la Hélade: Hades y Dioniso son un mismo dios. ${ }^{35}$ También desde Heráclito sabemos que el dios de la muerte y el dios del éxtasis de la vida, son uno y el mismo. Que hacer distinciones es estar dormidos ante la unidad que constituye la existencia. Estamos ante la mismidad entre la vida y la muerte, la coincidencia entre principio y fin (arche kai peras), que ignora fronteras entre nacimiento y muerte. ${ }^{36}$

En este sentido, es muy revelador cómo los allegados de una persona fallecida siguen escribiendo en su página de Facebook. Le confiesan cuánto la extrańan, la felicitan el día de su cumpleaños, "me sigues protegiendo desde el cielo", "eres la mejor madre del mundo"... lo hacen, además, dirigiéndose a la persona, en segunda del singular, como si los estuviera escuchando, como si ese fuese el medio propicio para seguir en contacto, como si estuviera viva. Hacerlo públicamente invita a que los demás también le escriban, y formen parte, de esa manera, del antídoto digital contra el olvido. Y ese "tú" al que se le habla nos permite pensar que hay algo ahí que debemos atender, hay un halo sanador en esta interacción en el más allá digital, hay un decirse de lo sentido que de otro modo no se dijo, que diluye barreras e implica al otro. Y hay "otro" porque hay una presencia que no podemos desestimar: notas de voz, opiniones, fotos, videos de restaurantes, aeropuertos, atardeceres, vinos, celebraciones, libros, conferencias... Estamos ante una (nueva) manera de la presencia que no nos sitúa en un monólogo o en un diálogo estrictamente imaginario. Hay una vitalidad capturada en los testimonios digitales de la cotidianidad, distinta de otros testimonios, fundamentalmente porque nuestras presencias virtuales tampoco distinguen si estamos vivos o muertos.

En efecto, las presencias virtuales son otra manera de la presencia, otra manera de estar. A través de cualquiera de nuestros dispositivos o aplicaciones nos hacemos presentes a miles de kilómetros de distancia, con la inmediatez de lo que ocurre ahora mismo en otro lugar geográfico distinto del nuestro, para formar parte de esa experiencia. Nuestras apariciones por Skype, por ejemplo, nos permiten otra experiencia con relación a la experiencia in situ-por así decirlo, pues ambas ocurren alli-, y no constituyen un "sustituto" de algo, como sostiene Bauman. ${ }^{37}$ Nuestra

\footnotetext{
35 Heráclito, frag. 15 (50 en Markovich). Cfr. Markovich, M., Heraclitus, Mérida, Universidad de Los Andes, 1968.

36 Heráclito, frag. 103 (34 en Marvovich).

37 Escribe Bauman, a propósito de la experiencia de escuchar a unos adolescentes en un tren, hablando por teléfono celular con sus padres: "Uno diría que están contando los minutos que los separan de sus seres queridos y que no ven la hora de poder mantener esas conversaciones cara a cara. Pero quizás no haya pensado que muchas de esas charlas por celular que usted escuchó por azar no eran el prolegómeno de una conversación más
} 
presencia virtual no es una prótesis de nuestra presencia porque, en efecto, estamos alli. Damos nuestra conferencia, si es el caso, interactuamos con la audiencia y no podemos asumir que eso no fue real, o no tan real, o que lo ocurrido fue una sustitución de otra cosa. Se trata de experiencias distintas, de un relacionarse diferente que permite que estemos, compartamos, conozcamos, de otra manera. Es imposible sostener que una experiencia sustituya a otra experiencia: las experiencias son diversas, distintas. Esto no niega que una experiencia nos pueda parecer mejor o más conveniente, como dice Protágoras, pero en ningún caso alguna podrá ser más verdadera. ${ }^{38} \mathrm{El}$ hombre con su aisthesis, ${ }^{39}$ percepción o experiencia, es la medida de lo que es y de lo que no: "¿no somos tú y yo hombres?” ${ }^{40}$ Desde la antigüedad sabemos que tenemos que vérnoslas con las diferencias de nuestras experiencias, y que no podemos desestimar ninguna como falsa o menos "rea"). Es interesante, además, la manera cómo se complica el lenguaje cuando queremos distinguir las presencias virtuales de las "físicas" o "reales" o "in situ". Como si las otras fuesen metafísicas, irreales o no estuviesen ocurriendo allí.

Esas presencias virtuales, por supuesto, pueden quedar "colgadas" en los portales digitales, propios y ajenos, y formar parte de los testimonios que vamos legando a la posteridad. Por lo tanto, la posibilidad de mostrarnos en la conferencia que dimos por Skype, ocurre en cualquier lugar, en cualquier momento y no tiene la menor importancia si estamos vivos o muertos. La interacción que genere con la audiencia digital no tiene nada que ver con nuestra situación de vida o muerte biológica. Es a esa "vitalidad" a la que me refiero con los testimonios digitales, a las interacciones que permite indefinidamente, a los cambios que puede sufrir, y a la presencia que da vida al "otro" que no es distinta de nuestra presencia digital estando vivos. Por

sustancial a producirse al llegar, sino un sustituto de ella. Que esas charlas no preparaban el terreno para algo real, sino que eran lo real en $s i$ [...]", Bauman, Z., Amor líquido, EspaEbook, 2003, p. 57. Aparte de lo extraño que resulta pensar en unos adolescentes contando los minutos para estar junto a sus padres, Bauman reclama algo igualmente extraño: que la conversación a través del celular no sea un prolegómeno -y no sabemos por qué habríamos de haberlo pensado-, y que sea un sustituto de lo real en sí. No pueden ser ni un prolegómeno ni un sustituto, por supuesto, porque son experiencias auténticas pero distintas de las otras, de las que Bauman llama "cara a cara". Y, tal vez lo más importante, porque las experiencias no se "sustituyen" entre sí. Asimismo, esas "charlas no preparan el camino para algo real", con toda razón, porque también son reales. ¿Qué puede significar que no lo sean? ¿Por qué sería más "sustancial" la conversación de los jóvenes -o de cualquiera- al llegar a su casa? Asumir este punto de vista, supone que hay experiencias más verdaderas que otras -en lugar de diferentes-, lo que es insostenible, como lo sabemos desde Protágoras, Nāgārjuna, Merleau-Ponty, o nuestra propia vida. Lo dicho y lo vivido a través del celular es distinto de otro tipo de experiencia. Habría que preguntarse, finalmente, y con especial ahínco desde Nāgārjuna, Protágoras o Rorty, qué es "lo real en sí". Pues no luce distinto de lo que ocurre en la experiencia. Como recordaremos a continuación, hay experiencias que pueden resultarnos más convenientes, sin duda, pero no más verdaderas. Ni más "sustanciales".

${ }^{38}$ Cfr. Platón, Teeteto, Madrid, Gredos, 1988, 167b.

39 Cfr. Teeteto, 152c; Rojas Parma, L., Protágoras y la significación de aisthesis, Revista de Filosofía, Universidad de Chile, vol. 71, 2015.

40 Teeteto, 152a. 
lo tanto, da ocasión a algo que no es, stricto sensu, un monólogo o un diálogo imaginario en Facebook, con alguien que haya fallecido.

Esos cambios que podremos sufrir en la sobrevivencia digital, incluso si nuestros testimonios no son intervenidos, cuestionan, por supuesto, nociones como el yo o la identidad. Pues, inevitablemente, todo esto va a cambiar. Las interpretaciones, asociaciones, experiencias que tenga el otro con nuestros testimonios, la manera como logre forjar su recuerdo, tal vez tenga poco o nada que ver con lo que nosotros asumimos como nuestra identidad. Esto, sin duda, no es ninguna novedad para la filosofía. Muchísimo menos para el pensamiento budista. La imposibilidad del yo, su ilusión o su fantasía, es de viejo cuño. En la vida digital solo vemos como se confirma o se recrea esta visión del hombre. Desde la noción fluyente y siempre cambiante del alma según Protágoras o Diotima, ya se nos devela la naturaleza del hombre en devenir, ajeno a certezas o pareceres inamovibles. Ni siquiera el conocimiento permanece el mismo, dice Diotima, porque no persiste en nosotros, porque en el cambio constante que es el alma lo olvidamos. La práctica no es más que un nuevo recuerdo que reemplaza el conocimiento que se ha ido, "hasta el punto de que parece el mismo". ${ }^{41}$ Es inevitable, igualmente, recordar también a Hume cuando nos dice:

En lo que a mí respecta, siempre que penetro más íntimamente en lo que llamo mí mismo tropiezo en todo momento con una u otra percepción particular, sea de calor o de frío, de luz o de sombra, de amor o de odio, de dolor o de placer. Nunca puedo atraparme a mí mismo en ningún caso sin una percepción. Cuando mis percepciones son suprimidas durante algún tiempo, como sucede por ejemplo en un sueño profundo durante el cual no me doy cuenta de mí mismo, puede decirse verdaderamente que no existo. ${ }^{42}$

La filosofía budista suscribiría las palabras de Hume, y la meditación profunda, especialmente las últimas líneas. ${ }^{43}$ La vida del hombre, dice Diotima, nunca es la misma, "sino que continuamente se renueva[...] y no solo en el cuerpo, sino también en el alma: los hábitos, caracteres, opiniones, deseos, placeres, tristezas, temores, ninguna de estas cosas jamás permanece la misma en cada individuo, sino que unas nacen y otras mueren". ${ }^{44}$ Somos un fluir constante de percepciones y experiencias que diluyen las posibilidades de una identidad o un yo. Para Nāgārjuna el yo y sus percepciones no son más que vacío y, como Hume, tampoco podría alcanzarse a sí mismo. No hay percepción del yo, dice Hume, y si la hubiese, el rugido

\footnotetext{
41 Banquete, 208a.

${ }^{42}$ Hume, D., Tratado de la naturaleza humana, Barcelona, Orbis, 1984, libro I, 4a parte, sección VI.

${ }^{43}$ Cfr. Mori, M., op. cit. p. 26 y ss.

${ }^{44}$ Banquete, 207e.
} 
de león igualmente la develaría como sūnyatā. "Porque la palabra 'yo' es tan hueca como la palabra 'muerte". ${ }^{45}$ No hemos contado nunca - desde esta mirada de las cosas- con un yo verdadero y estable. Pues "El yo único y auténtico -afirma Hararies tan real como el alma cristiana eterna, Santa Claus y el conejo de Pascua. Si miro en mi interior más profundo, la aparente unidad que damos por sentada se disuelve en una cacofonía de voces en conflicto, ninguna de las cuales es 'mi yo verdadero'". ${ }^{46}$ Así las cosas, despojados de un yo que nos distinga del devenir, de las voces contradictorias, de un alma estable, ¿cuál es la diferencia con nuestra vida digital y sobreviviente? Lo mismo tenemos que decir sobre la identidad: no hay una única voz, interioridad o yo personal, que invariablemente nos otorguen identidad. En realidad, como sostiene Rosset, solo contamos con una identidad social hecha de nuestros comportamientos y de las percepciones que los otros tienen de nosotros. "Fuera de los signos y de los actos que emanan del yo y me identifican como quien soy, no hay nada que sea mío ni propio de mî". ${ }^{47}$ Lo que equivale a decir que el yo no es más que mis actos, lo que hago en el mundo, lo que puedo mostrar. "Ninguno llega a constituir la unidad de una identidad personal -continúa Rosset-, sino una suma aleatoria de cualidades que se le reconocen o no al albur del humor de quienes le rodean". ${ }^{48} \mathrm{Si}$ esto es así, es preciso insistir en la pregunta: ¿cuál es la diferencia con nuestra identidad digital, con nuestras andanzas digitales post mortem? En este sentido, cuestionarse por la identidad que podamos asumir en ese devenir digital, implica cuestionarse por la noción misma de identidad, que se nos devela igualmente ilusoria en la vida biológica. Si somos "una suma aleatoria de cualidades", tampoco somos muy distintos de un avatar que transita en las redes digitales.

Lo que viene a nuestro encuentro con esta inmortalidad digital no es, entonces, librar una batalla contra la muerte prolongando indefinidamente los tiempos del bios; es la muerte que comienza a perder relevancia, a desvanecerse, junto a la vida biológica. El "yo" y la "muerte" son palabras huecas. Así, el rito de la despedida, el duelo necesario que lo acompaña, la desaparición inevitable, se diluyen poco a poco en esa inmortalidad de la nube que nos resguarda para siempre. La "sustancia biológica" de la vida también se va disipando, pues su inmortalidad ya no la requiere. Si es inmortalidad ¿por qué habría de requerirla? De nuevo se escucha el bramido del Logos efesio: vida y muerte son lo mismo. Pues "los opuestos vida y muerte son partes inseparables de uno y mismo continuo ${ }^{2}{ }^{49}$ En las enigmáticas palabras de

\footnotetext{
45 Rorty, R., op. cit. p. 43. Esto lo dice Rorty comentando el argumento de Epicuro sobre la muerte. Cfr. el capítulo "La contingencia del yo", op. cit., pp. 43-62.

${ }^{46}$ Harari, Y. N., op. cit., p. 305.

47 Rosset, C., Lejos de mí, Barcelona, Marbot, 2007, p. 6.

48 Rosset, C., op. cit., p. 25. Cursivas añadidas.

49 Markovich, M., op. cit., p. 58. Cursivas ańadidas.
} 
Heráclito: Nombre del arco vida (Bios), y su obra la muerte. ${ }^{50}$ La vida implica y obra la muerte, por supuesto, pero son lo mismo. Esa unidad de la physis, en la que los contrarios son lo mismo, adquiere un tono revelador en estos tiempos digitales. Somos vida y somos muerte. ${ }^{51}$

Desde la orilla griega del río del olvido, zoe y bios siguen teniendo la última palabra -o la primera- porque, a pesar de todo lo que podamos decir de esta inmortalidad digital, aún tenemos que nacer. ${ }^{52}$

\section{$\delta$. Ruge el león: somos inmortales}

Es tiempo, sin embargo, de volver a la ribera del Ganges, y pensar en el "surgimiento condicionado" que significa venir a la vida, y en su inevitable vaciedad. ${ }^{53}$ Hemos visto cómo todo lo que tiene causa tiene fin, pues todo es, simplemente, un agregado $\left(\right.$ skandha) que espera a ser disuelto. ${ }^{54}$ Desde el punto de vista de Nāgārjuna somos vacío, insustanciales, condicionados y, con ello, ilusorios. Por lo tanto, si somos rigurosos, no hallaremos diferencias entre nuestra presencia "física" y nuestra presencia virtual: ambas son condicionadas, dependientes, efímeras e insustanciales. La única diferencia es el tipo de agregados que nos compone -la piel o la memoria, los bytes o los algoritmos-, pero en nada nos distingue de la vaciedad. Ni nosotros ni nuestras apariciones virtuales cuentan con un ser propio.

50 Frag. 48 (39 en Markovich). Traducción modificada.

51 La inmortalidad digital permite conciliar, desde este punto de vista, al menos, ciertos argumentos complejos con relación a la muerte. Pues al no poder distinguirla de la vida, en sentidos profundos como los de Heráclito o el mismo Nāgārjuna, renunciamos a su negación. En efecto, argumentos que cuestionan la inmortalidad personal que se desprende del transhumanismo, centran allí su crítica: "Con todo ello lo que se revela es que la misma condición de posibilidad de todo el proyecto, constitutivo del trans y del posthumanismo, de la prolongación de la vida hábil es el mismo límite ideal que pone la creencia, más bien la fantasía, de la inmortalidad personal. La muerte, entonces, y esto no es de ninguna manera ninguna novedad, no dejaría de ser degradada a accidente, mera casualidad explicable por las circunstancias siempre azarosas que concurren en el caso del fallecimiento concreto, pero en absoluto algo consustancial a la vida”, Rodríguez, M., op. cit., p. 72. Sin embargo, desde la inmortalidad digital la muerte se nos diluye en una permanencia que tampoco es biológica. El punto que se destaca, sin embargo, y que nos permite especialmente la mirada de India, es la indistinción última entre lo biológico y lo digital. A partir de esto, finalmente, tomo distancia de los argumentos sobre la muerte de Rosi Braidotti, en su texto Lo posthumano. Aunque son innegables algunas similitudes, como el continuum vida-muerte, obedecen más a su uso clásico de zoe, y al fondo heracliteano de su planteamiento, no reconocido, por demás, que a una auténtica afinidad con relación a la inmortalidad digital que ahora se estudia. Cfr. Braidotti, R., Lo posthumano, Barcelona, Gedisa, 2015, pp. 130 y ss.

52 Es interesante cómo incluso la propuesta de Kurzweil de un futuro de máquinas súper inteligentes, aún se sostiene en lo humano. Pues esa súper inteligencia es una suerte de elevación suprema de la inteligencia humana: "las máquinas futuras serán humanas, aunque no sean biológicas", Cfr. Kurzweil, R., La singularidad está cerca. Cuando los humanos trascendamos la biología, Berlín, Lola Books, 2021, p. 33.

53 Cfr. Tola, F. y Dragonetti, C., op. cit., n. 95, p. 169; n. 156, p. 189.

${ }^{4}$ Cfr. Estrofa 3, Lokätītastava, op. cit., p. 160. 
Por ello, que nosotros respiremos o recordemos, no nos hace más "reales" o, en última instancia, distintos.

Dice Nāgārjuna en el Lokātìtastava: "lo que surge en dependencia, eso no surge". ${ }^{55}$ Como todo surge dependiente de su causa, es evidente que nada surge. Además, las causas de las cosas también son dependientes de otras, en consecuencia, ni ellas ni sus efectos se apartan de la ilusión. ${ }^{56}$ Con esto quiero decir, desde la mirada que nos brinda el budismo mahāyāna, que ni siquiera el nacimiento es garantía para poseer un ser propio y, así, ser distintos de la vaciedad. Nuestra insustancialidad es parte de la forma de ser de las cosas, de manera que cualquier aparición posible, virtual o no, sigue siendo parte de lo mismo: sünyata..${ }^{57}$ Lo dice Nāgārjuna a Buda: "Tú has dicho que lo que surge de condiciones, no surge; eso no ha nacido con ser propio, por eso Tú has proclamado que es vacío" . ${ }^{58}$ Si no contamos con ese ser propio ni somos sustanciales, en fin, si ni siquiera "somos", no lucimos muy distintos de nuestra vida del más allá digital. Estamos hablando de una inmortalidad que permite la tecnología digital, y estos argumentos tratan de dar cuenta de las diferencias que se quieran establecer entre la vida biológica y los testimonios digitales que nos sobrevivirán. Si para Heráclito la vida y la muerte no son distintos, es porque la identidad de esos contrarios la otorga la physis, la realidad única de todas las cosas que nada tiene que ver, por supuesto, con el vacío. Pero la physis-Logos es lo que unifica, homogeniza la pluralidad del kosmos e irrumpe contra jerarquías posibles entre lo que existe. En ese punto, tal vez, se nos haga próximo a lo que significa el sünyatā: realidad de todo lo que "existe", y que igualmente unifica esa pluralidad ilusoria que conforma el mundo. Lo que quiero destacar, a propósito de nuestra discusión, es que si para el griego, la vida y la muerte son parte del mismo continuum, y su indistinción es desconocimiento de la verdad de las cosas, para la voz de India la muerte es, stricto sensu, imposible. En efecto, si no contamos con sustancialidad y nuestro aparecer en el mundo es ilusorio, poco tendremos que esperar de la posibilidad de la muerte. Dice Nāgārjuna: "Pues, dándose la identidad de ambos [vida y muerte], la destrucción no es posible para la existencia; dándose la diferencia la destrucción no

\footnotetext{
55 Estrofa 9, op. cit., p. 163; cfr. estrofa 17, op. cit., p. 167.

${ }^{56}$ Cfr. Lokātìtastava, estrofa 4, op. cit., p. 161. "Examinando atentamente la nada, observa: 'no hay nada', y entonces te apoyarás en esto y franquearás la inundación”, palabras de Buda en el Suttanipāta, en Bareau, A., op. cit., p. 209.

57 En la estrofa 13 del mismo Lokātītastava, y con un tono que recuerda a Gorgias, Nāgārjuna expone la imposibilidad del surgimiento de algo: "Una cosa no surge si existía (antes de surgir), ni tampoco, si no existía (antes de surgir), ni tampoco, si existía y no existía (antes de surgir); ni tampoco surge de sí, ni de otro, ni de ambos. ¿Cómo surge?”. Cfr. Sexto Empírico, Contra los profesores, Madrid, Gredos, 1997, VII 65ss., De Melisso, Jenófanes y Gorgias, V-VI, 979a-980b21, en Sofistas: testimonios y fragmentos, Madrid, Gredos, 1996, p. 175-183; 184-190.

58 Estrofa 3, Achintyastava, op. cit., p. 189.
} 
es posible para la existencia" ${ }^{59}$ Con unos argumentos que nos recuerdan un poco a Platón, ${ }^{60}$ la diferencia o la identidad entre la existencia y la destrucción supondrían que la existencia es eterna. Y es evidente que no es así, pues todo depende de una causa y es condicionado. La muerte, entonces, se nos muestra imposible.

¿Qué significa esto, para nuestra inmortalidad digital? Que podemos hablar de inmortalidad en estos predios de la tecnología digital, que nuestras aventuras futuras no son indiscutiblemente distintas de las que hoy vivimos, que no hay que desestimar esta manera de permanecer y de ser hallados en tiempos venideros. Si no somos más que ilusión, actos mágicos de la mente, espejismos y burbujas de espuma, ${ }^{61}$ seres efímeros, ${ }^{62}$ nuestras presencias virtuales no son distintas de "nosotros". No podemos sostenernos en experiencias reales y otras irreales, ni en la permanencia de algo que la exima de su condición transitoria. Por tanto, si pensamos en nuestros testimonios digitales, ¿podríamos decir, por ejemplo, que las fotos, textos o videos, no tienen "alma"? ¿Que allí no estamos realmente "nosotros"? Es evidente que no. Esos testimonios pueden resguardar toda el alma y el corazón tal vez perdidos en otro tiempo de la vida "real". Pueden traernos de vuelta una vitalidad que de otra forma estaría totalmente perdida. Aunque incluso el alma, por estos lados indios del río, y de los filósofos enemigos del yo, también es ilusoria. Si el "surgimiento es similar a un sueño", ${ }^{63}$ como dice en tantas ocasiones Nāgārjuna, y el surgimiento es venir a la vida, ¿cómo nos hacemos la pregunta por lo real? Si la vida se devela nuevamente un sueño, entonces, aquel soliloquio de Calderón de la Barca vuelve a resonar desde nuestra memoria, y Segismundo vuelve a cantarnos la verdad profunda de las cosas.

De esta manera, sin jerarquías ontológicas, sociales o políticas, sin abolengos ni genialidad, hemos conquistado una forma de no esfumarnos, de inmortalidad. El discreto lugar que nos tocó ocupar en el mundo hoy puede dejar algún rastro, una huella, como si la vida, a pesar de todo, hubiese valido la pena. Podemos dejar un symbolon al alma que quiera ir en nuestra búsqueda, aquella mitad de tablilla que entregaban los griegos a algún visitante, para que sus descendientes, en el futuro, en

\footnotetext{
59 Estrofa 16, Lokātìtastava, op. cit., p. 167. "Como un hijo que nace, existe y perece en un sueño, así Tú has dicho que el mundo, de acuerdo con la realidad, no nace, no existe, no perece”, estrofa 25, Achintyastava, op. cit., p. 198.

${ }^{60}$ Cfr. Fedón, 105c y ss.

${ }^{61}$ Cfr. Estrofas 4, 5, 18, 24, Achintyastava, op. cit., pp. 189-190; 195; 197.

${ }_{62}$ Esquilo, Prometeo encadenado, v 250.

${ }^{63}$ Estrofa 17, Lokātītastava, op. cit., p. 167. Cfr. Paramārthastava, estrofas 1-11, op. cit., pp. 213-216. "Nāgārjuna equates emptiness in its mode as an attribute with dependent co-arising, the casual pattern underlying the events of Samsāra; he equates emptiness as a perceptual mode with nirvāna”, Robinson, R., Johnson, W., op. cit., p. 88 .
} 
alguna visita, pudiesen reconocer a los que portaban la otra mitad. ${ }^{64} \mathrm{La}$ tecnología digital permite que nosotros mismos entreguemos nuestro symbolon al descendiente o al viejo amigo del hogar que regresa por nosotros. La vida inmortal de las redes, la que desafía con ferocidad al olvido, seguirá su propio curso, hasta que algún meteorito catastrófico venga de nuevo a poner fin a todo.

Esta inmortalidad digital, esta sobrevivencia de nuestros pasos de hombres comunes, la vida que tendrá que vérselas con los testimonios eternos y la memoria que tendrá que aprender a forjar sus recuerdos, dan cuenta de una época en la que lo humano está repensándose. Nociones que asumíamos inquebrantables, como la muerte, la duración promedio de la vida, el cuerpo biológico o la desaparición insalvable de nuestras experiencias, ahora están sometidas a transformaciones que nos llevan a esas fronteras donde se devela lo posthumano. Ahora lo humano se encuentra o se fusiona con lo otro, curiosamente, animal o máquina, y devela nuevas experiencias y una nueva condición en el mundo, pero que es tan antigua como Gilgamesh o los profundos inicios de la filosofía.

Terminemos con unas palabras de Sócrates, cuando dice a Menón:

"Es evidente, en efecto, que en el transcurso del tiempo todo lo es y no lo es un ser humano". ${ }^{65}$

${ }_{64}$ Cfr. Banquete, 191 d; Gadamer, H.-G.: La actualidad de lo bello, Barcelona, Paidós, 1991, pp. 83-85.

${ }^{65}$ Menón, 86a. 


\section{REFERENCIAS BIBLIOGRÁFICAS}

Aristóteles, Acerca del alma, Madrid, Gredos, 1994.

Arnau, J., La palabra frente al vacío. Filosofía de Nägārjuna, México, Fondo de Cultura Bareau, A., Buda, vida y pensamiento, Madrid, Edaf, 1981. Económica, 2005.

Bauman, Z., Amor líquido, EspaEbook, 2003.

Braidotti, R., Lo posthumano, Barcelona, Gedisa, 2015.

Chrétien, J.-L., Lo inolvidable y lo inesperado, Salamanca, Sígueme, 2002.

De Tales a Demócrito: fragmentos presocráticos, Madrid, Alianza, 1998, p, 164. Traducción de Alberto Bernabé.

Detienne, M., Dioniso a cielo abierto, Barcelona, Gedisa, 1997, p. 36.

Diéguez, A., Transhumanismo, Barcelona, Herder, 2017.

Esquilo, Prometeo encadenado, Gredos, Madrid, 2006.

Gadamer, H.-G.: La actualidad de lo bello, Barcelona, Paidós, 1991.

Gadamer, H.-G., El inicio de la filosofía occidental, Barcelona, Paidós, 1995.

García Gual, C., Antología de la poesía lírica griega, Madrid, Alianza, 2008.

Garfield, J.L., The Fundamental Wisdom of The Middle Way, Oxford, Oxford University Press, 1995.

Gómez Fernández, A., "Nagarjuna y la dialéctica del origen condicionado", en Pensamiento, Universidad de Comillas, Vol. 64, 2008.

Harari, Y. N., Homo Deus, Penguin Random House, 2016. https://doi. org/10.17104/9783406704024

Harvey, P., El budismo, Cambridge University Press, traducción española, 1998.

Hesíodo, Teogonía, Madrid, Gredos, 1990.

Homero, Ilíada, Madrid, Gredos, 1991.

Hughes, J., Using Neurotechnologies to Develop Virtues - A Buddhist Approach to Cognitive Enhancement, https://ieet.org/index.php/IEET2/more/hughes20121016.

Hume, D., Tratado de la naturaleza humana, Barcelona, Orbis, 1984. 
Kalupahana, D., The Philosophy of The Middle Way, Albany, State University of New York Press, 1986.

Kurzweil, R., La singularidad está cerca. Cuando los humanos trascendamos la biología, Berlín, Lola Books, 2001.

Markovich, M., Heraclitus, Mérida, Universidad de Los Andes, 1968.

Mazocco, R., Transhumanism, Engineering the Human Condition, Springer Praxis Books, 2019. https://doi.org/10.1007/978-3-030-04958-4

Mori, M., The Buddha in the Robot, Tokyo, Kosei Publishing, 1985.

Nāgāriuna, Lokātītastava, en Tola, F., y Dragonetti, C., (compiladores y traductores): Filosofía budista, Buenos Aires, Las cuarenta, 2012.

Nāgārjuna, Achintyastava, en Tola, F., y Dragonetti, C., (compiladores y traductores): Filosofía budista, Buenos Aires, Las cuarenta, 2012.

Nāgārjuna, Niraupamyastava, en Tola, F., y Dragonetti, C., (compiladores y traductores): Filosofía budista, Buenos Aires, Las cuarenta, 2012.

Parain, B., (compilador), Historia de la filosofía, México, Siglo XXI, 1990.

Platón, Ion, Gredos, Madrid, 1981.

Platón, Teeteto, Gredos, Madrid, 1988.

Platón, Banquete, Gredos, Madrid, 1997.

Platón, Fedón, Gredos, Madrid, 1997.

Platón, Fedro, Gredos, Madrid, 1997.

Platón, Menón, Gredos, Madrid, 1999.

Platone, Tutte le opere, Roma, Grandi Tascabili Economici, 1999. Edición bilingüe.

Rodríguez González, M., “Tecnotrascendencia como ilusión narcisista”, Daimon. Revista Internacional de Filosofía, no 76, 2019. https://doi.org/10.6018/ daimon/273521

Robinson, R., Johnson, W., The Buddhist Religion, Belmont CA, Wadsworth Publishing Co, 1997.

Rojas Parma, L., "Protágoras y la significación de aisthesis", Revista de Filosofía, Universidad de Chile, vol. 71, 2015. https://doi.org/10.4067/S071843602015000100011 
Rorty, R., Contingencia, ironía y solidaridad, Barcelona, Paidós, 1991.

Rosset, C., Lejos de mí, Barcelona, Marbot, 2007.

Sexto Empírico, Contra los profesores, Madrid, Gredos, 1997.

Sofistas: testimonios y fragmentos, Madrid, Gredos, 1996.

Sófocles: Edipo en Colono, Madrid, Gredos, 2006.

Sloterdijk. P., "El hombre operable", conferencia dictada en el Center of European Studies, http://www.observacionesfilosoficas.net/download/hombreoperable.pdf.

Vélez de Cea, A., "Nāgārjuna y la filosofía del Buddha", en Contrastes, Revista internacional de filosofía, Universidad de Málaga, Vol. 3, 1998. https://doi. org/10.24310/Contrastescontrastes.v3i0.1657

Villarroel, R., "Consideraciones bioéticas y biopolíticas acerca del transhumanismo. El debate en torno a una posible experiencia posthumana", en Revista de Filosofia, Universidad de Chile, Vol, 71, 2015. https://doi.org/10.4067/S071843602015000100014

Walser, J., Nāgārjuna in context: Mahāyāna Buddhism and The Early Indian Culture, New York, Columbia University Press, 2005. https://doi.org/10.7312/ wals 13164

Wilkins, H., Mitología hindú, Barcelona, Edicomunicación, 1998.

Zimmer, H., Mitos y simbolos de la India, Madrid, Siruela, 2008.

DOI: https://doi.org/10.15366/bp2021.27.017

Bajo Palabra. II Época. No 27. Pgs: 323-348 
